\title{
Depressive symptoms and adherence to cardiometabolic therapies across phases of treatment among adults with diabetes: the Diabetes Study of Northern California (DISTANCE)
}

Patient Preference and Adherence

24 March 2017

Number of times this article has been viewed

\section{Amy M Bauer' \\ Melissa M Parker² \\ Howard H Moffet ${ }^{2}$ \\ Dean Schillinger ${ }^{3,4}$ \\ Nancy E Adler ${ }^{5}$ \\ Alyce S Adams ${ }^{2}$ \\ Julie A Schmittdiel ${ }^{2}$ \\ Wayne J Katon ${ }^{1, \dagger}$ \\ Andrew J Karter ${ }^{2}$}

'Department of Psychiatry and Behavioral Sciences, University of Washington School of Medicine, Seattle, WA, ${ }^{2}$ Kaiser Permanente Northern California, Oakland, ${ }^{3}$ Division of General Internal Medicine, University of California, San Francisco, ${ }^{4}$ Center for Vulnerable Populations, San Francisco General Hospital and Trauma Center,

${ }^{5}$ Department of Psychiatry and Pediatrics, Center for Health and Community, University of California, San Francisco, CA, USA

tDr Wayne J Katon passed away on March I, 20I5
Correspondence: Amy M Bauer Department of Psychiatry and Behavioral Sciences, University of Washington School of Medicine, 1959 NE Pacific Street, Box 356560 , Seattle, WA 98195-6560, USA

$\mathrm{Tel}+\mathrm{I} 2062218385$

Fax + I 2065439520

Email abauerl@uw.edu
Objective: Among adults with diabetes, depression is associated with poorer adherence to cardiometabolic medications in ongoing users; however, it is unknown whether this extends to early adherence among patients newly prescribed these medications. This study examined whether depressive symptoms among adults with diabetes newly prescribed cardiometabolic medications are associated with early and long-term nonadherence.

Patients and methods: An observational follow-up of 4,018 adults with type 2 diabetes who completed a survey in 2006 and were newly prescribed oral antihyperglycemic, antihypertensive, or lipid-lowering agents within the following year at Kaiser Permanente Northern California was conducted. Depressive symptoms were examined based on Patient Health Questionnaire-8 scores. Pharmacy utilization data were used to identify nonadherence by using validated methods: early nonadherence (medication never dispensed or dispensed once and never refilled) and long-term nonadherence (new prescription medication gap [NPMG]: percentage of time without medication supply). These analyses were conducted in 2016.

Results: Patients with moderate-to-severe depressive symptoms had poorer adherence than nondepressed patients ( $8.3 \%$ more patients with early nonadherence, $P=0.01 ; 4.9 \%$ patients with longer NPMG, $P=0.002 ; 7.8 \%$ more patients with overall nonadherence [medication gap $>20 \%$ ], $P=0.03$ ). After adjustment for confounders, the models remained statistically significant for new NPMG (3.7\% difference, $P=0.02)$. There was a graded association between greater depression severity and nonadherence for all the models (test of trend, $P<0.05$ ).

Conclusion: Depressive symptoms were associated with modest differences in early and long-term adherence to newly prescribed cardiometabolic medications in diabetes patients. Interventions targeting adherence among adults with diabetes and depression need to address both initiation and maintenance of medication use.

Keywords: medication adherence, depression, diabetes mellitus, type 2 diabetes, Patient Health Questionnaire-8, PHQ-8, antihypertensive, hypoglycemic, hypolipidemic agents, pharmacoepidemiology, observational cohort study

\section{Introduction}

Medication nonadherence is a modifiable contributor to morbidity and mortality associated with chronic conditions, such as diabetes and cardiovascular disease, and thus serves as a potential target for tertiary preventive interventions. ${ }^{1}$ The societal burden of medication nonadherence is substantial; in the USA, nonadherence has been estimated to account for 125,000 annual deaths, a major proportion of 
preventable hospitalizations, and to carry economic costs between $\$ 100$ and $\$ 300$ billion each year. ${ }^{2}$ Past research to identify risk factors for medication nonadherence has focused on nonadherence among ongoing (prevalent) medication users, ${ }^{3,4}$ termed secondary nonadherence. However, studies on secondary nonadherence underestimate overall medication nonadherence because they systematically exclude people who are nonadherent in the earliest phases of treatment, that is, those who never fill a medication prescription or those who fill an initial prescription but never refill it. ${ }^{5-7}$ Nonadherence at this early phase is important because such individuals do not go on to become ongoing users of the medication and therefore do not receive the potential benefits of treatment as a prevention of premature morbidity and mortality. Recent methodological innovations allow the characterization of adherence in new prescription cohorts (patient cohorts in which baseline is the date of first medication prescribed), thus enabling researchers to more comprehensively evaluate the public health burden and correlates of nonadherence over the entire course of treatment. ${ }^{6}$

Depression, which is common among people with chronic diseases including diabetes, ${ }^{8-13}$ has been identified as a risk factor for secondary medication nonadherence among adults with diabetes. ${ }^{14-16}$ In a recent systematic review, depression and outof-pocket costs were among the few patient-, treatment-, and system-level factors that demonstrated consistent, significant associations with adherence to diabetes medications across multiple studies employing differing methods. ${ }^{4}$ Although reasons for the association between depression and secondary adherence are not fully established, related research has found that, among people with diabetes, those with comorbid depression have poorer self-care in multiple domains than nondepressed counterparts. ${ }^{14}$ Depression has negative effects on cognitive and affective functioning that may serve as barriers to participation in self-care broadly and medication adherence specifically. For example, depression negatively affects motivation and executive functioning and includes psychological effects such as hopelessness, helplessness, poor self-efficacy, and feelings of low self-worth, all of which may interfere with activities needed for effective self-care.

It is not known whether the well-established association between depression and secondary medication adherence extends to early nonadherence. This knowledge is important for understanding the overall public health impact of depression, which may be underestimated in the literature on secondary adherence. The present study examined whether depressive symptoms among adults with type 2 diabetes were associated with initiation and maintenance of newly prescribed cardiometabolic therapies. It is hypothesized that patients with greater depressive symptom severity would have poorer early and long-term adherence than those without depressive symptoms.

\section{Patients and methods Setting and study population}

Kaiser Permanente Northern California (KPNC) is a large integrated health care delivery system serving $\sim 30 \%$ of the catchment population of Northern California. The KPNC membership is ethnically diverse and sociodemographically similar to the population of the region, except for the extreme tails of the income distribution. ${ }^{17}$ The Diabetes Study of Northern California (DISTANCE) surveyed an ethnically stratified, random sample of adult (aged 30-75 years) health plan members from the KPNC Diabetes Registry in 2005-2006. The methods employed to construct the KPNC Diabetes Registry and the DISTANCE sample have been previously described in detail. ${ }^{18}$ There were no additional exclusion criteria for the survey. The overall eligibility-adjusted response rate was $62 \%$, yielding a final sample of 20,188 participants. ${ }^{18}$ Participants completed a written survey (33.1\%), a web-based survey (15.2\%) in English, or a computer-assisted telephone interview (51.7\%) in English, Spanish, Cantonese, Mandarin, or Tagalog. The KPNC Institutional Review Board (IRB) approved this study. The requirement that informed consent be obtained from study participants was waived by the IRB; answering any survey questions constituted consent.

The present study examined medication nonadherence in patients with type 2 diabetes during a period of 24 months following a new prescription order for any of three types of common cardiometabolic medications: oral antihyperglycemic agents, antihypertensive agents, and lipid-lowering agents. This study identified the 4,018 DISTANCE survey respondents who: 1) had a new prescription (index prescription) for an oral antihyperglycemic agent $(n=1,481)$, an antihypertensive agent $(n=1,620)$, or a lipid-lowering agent ( $\mathrm{n}=917$; refer Table $\mathrm{S} 1$ for complete medication list) within 1 year following survey completion, 2) were not previously dispensed the same medication in the 2 years preceding the index prescription date, 3 ) had continuous pharmacy benefits for at least 2 years before and after the index prescription date, and 4) completed the survey items assessing depressive symptoms (refer Figure S1 for details of cohort creation).

\section{Exposure}

Depressive symptoms were assessed by using the Patient Health Questionnaire (PHQ) that asks about the presence 
of depressive symptoms over the past 2 weeks. ${ }^{19,20}$ The PHQ has been widely validated as a measure for detecting the presence of clinically significant depressive disorders and is brief, easy to administer, and available in numerous languages. ${ }^{20-24} \mathrm{~A}$ diagnostic meta-analysis found a sensitivity of 0.80 and specificity of 0.92 for the detection of major depressive disorder. ${ }^{25}$ The present study used the PHQ-8 that is most commonly used for survey research given the inability to respond appropriately and in a timely fashion to positive suicidal ideation when administered via a written survey. (The PHQ-9 includes an additional item assessing thoughts of death or self-harm and is therefore more frequently employed in the clinical setting). ${ }^{19,20}$ Past research has demonstrated that scores of the PHQ-8 and PHQ-9 are highly correlated ( $r \mathrm{~s} \geq 0.997$ ), both measures have similar operating characteristics, and identical scoring cut-points can be used. ${ }^{19,20}$ The PHQ- 8 is scored from 0 to 24 and based on established cut-points; depressive symptom severity was coded as "none" (score 0-4), "mild" (score 5-9), or "moderate/severe" (score $\geqq 10){ }^{20,23}$

\section{Outcomes}

Pharmacy prescribing and dispensing data for the index prescriptions were used to calculate several indicators of nonadherence. Although pharmacy utilization is a distinct behavior from medication-taking, prior research has established the validity of this method. ${ }^{6,26}$ Early nonadherence was defined as either no dispensing of the index prescription within 60 days of the date it was ordered or the dispensing of the index prescription once but no additional dispensing of that medication (ie, no refill) within the period defined by the number of days' supply of medication dispensed plus a 90-day grace period. A continuous and comprehensive measure of nonadherence, new prescription medication gap (NPMG), was also calculated. This measure provides an estimate of the percentage of time without a supply (ie, gaps) of the index prescription during the 24 months after the initial order. ${ }^{6} \mathrm{NPMG}$ is calculated by using the daily dosage of medication prescribed, the number of pills dispensed, and dispensing dates over 24 months to estimate gaps in medication supply. By using NPMG, the patients were categorized as "nonadherent" overall if they lacked medication supply for at least $20 \%$ of the time (ie, NPMG $>20 \%$ ). For patients who had more than one new prescription, only adherence to the first medication prescribed for any of the three indications was assessed. For patients whose dispensing data indicated a switch from the index prescription to an alternate medication within the same drug class between 3 months prior and
1 month after the discontinuation date, the discontinuation of the index prescription was considered to be clinically recognized rather than an indicator of nonadherence. In such instances, follow-up as of the date of switch to the alternate medication was censored.

\section{Covariates}

Participants self-reported sociodemographic information (ie, age; gender; race/ethnicity: white, African-American, Latino, Asian-American, Filipino, or other/unknown/multiracial; marital status: married/partnered, single/separated/ divorced/widowed) and a history of any of the following: myocardial infarction, cerebrovascular accident, coronary artery disease (as indicated by coronary artery bypass surgery or angioplasty), lower extremity amputation, or renal failure requiring dialysis or transplantation. Missing survey data on diabetes complications were imputed using data on complications obtained from the electronic medical record.

\section{Data analysis}

Modified Poisson regression models were specified to estimate the relative risk (RR) of nonadherence for those with mild or moderate/severe depressive symptoms compared with those with none,${ }^{27}$ and modified least squares regres$\operatorname{sion}^{28}$ was employed to generate the predicted probability for each measure of nonadherence for each depressive symptom category. To assess whether nonadherence was greater among those with higher depression symptom severity, a Cochran-Armitage test for trend was applied to the predicted probabilities from the unadjusted and adjusted models for dichotomous outcomes (ie, adherent vs nonadherent). A generalized linear regression model was specified to evaluate the relationship between depressive symptom category and the percentage of time without pill supply (continuous NPMG). A directed acyclic graph (DAG) depicting hypothesized causal relationships and temporal ordering between the exposure (depressive symptom category) and outcomes of interest (measures of adherence) was constructed (refer Figure S2, for the graph and its interpretation). ${ }^{29,30}$ Then, established DAG rules were used to determine the subset of covariates (potentially confounding variables) required in adjusted models to estimate the unbiased direct effect of depressive symptoms on medication adherence. In accordance with the findings from the present DAG analysis, each model was adjusted by including age, gender, race/ethnicity, marital status, and diabetes complications as covariates (described in Covariates section). All the models were expansion-weighted to accommodate the race/ethnicity-stratified 
sampling design (nonproportional sampling fractions) of the original DISTANCE survey and further weighted for survey nonresponse by using the Horvitz-Thompson method. ${ }^{31}$ Analyses were completed in 2016.

\section{Results}

Among 4,018 patients who were prescribed a new cardiometabolic medication, $2,573(64.0 \%)$ patients were categorized as having no depressive symptoms, and the remaining $1,445(36.0 \%)$ were categorized as having mild (935, 23.3\%) or moderate/severe $(510,12.7 \%)$ depressive symptoms. Depressive symptoms were significantly associated with younger age, female gender, low educational attainment, race/ethnicity (particularly Latinos), unmarried status, the history of diabetes complications, and number of medications (Table 1).

Overall, early nonadherence was common, with $27.9 \%$ of patients either never filling or never refilling their newly prescribed cardiometabolic medication. Over the course of 2 years following a new prescription, on average, patients were lacking medications for 194 days (ie, NPMG =27\%), and $39.3 \%$ of patients were categorized overall as nonadherent (ie, NPMG >20\%).

\section{Associations between depressive symptoms and nonadherence}

Nonadherence to cardiometabolic medications was greater among patients with moderate/severe depressive symptoms than patients with no depressive symptoms. This pattern held for all indicators of nonadherence (Table 2). There was an $8.3 \%$ increase in early nonadherence $(\mathrm{RR}=1.33, P=0.006)$, a $7.8 \%$ increase in overall nonadherence (NPMG $>20 \%$; $\mathrm{RR}=1.22, P=0.02$ ), and $4.9 \%$ greater days without pill supply (NPMG; $P=0.002$ ). The point estimates changed only minimally after adjustment for age, gender, race/ethnicity, marital status, and diabetes complications. Only the model for NPMG specified as a continuous variable remained statistically significant after adjustment (3.7\% greater days without supply among patients with moderate/severe depressive symptoms than patients with no depressive symptoms; $P=0.02$ ). However, the Cochran-Armitage test for trend consistently demonstrated that nonadherence increased significantly as depressive symptoms increased with and without adjustment (early nonadherence: $P<0.0001$ [unadjusted] and $P=0.0028$ [adjusted]; and overall nonadherence [NPMG $>20 \%$ ]: $P=0.0002$ [unadjusted] and $P=0.0118$ [adjusted]). Similarly, the linear regression model also demonstrated a significant

Table I Demographic and clinical characteristics by depressive symptom category $(n=4,0$ I 8$)$

\begin{tabular}{|c|c|c|c|c|}
\hline & \multicolumn{3}{|c|}{ Depressive symptom severity } & \multirow[t]{2}{*}{$P$-value } \\
\hline & None & Mild & Moderate/severe & \\
\hline Total & $2,573(64)$ & $935(23)$ & $510(13)$ & \\
\hline Age (years) & & & & $<0.0001$ \\
\hline $30-45$ & $239(9.3)$ & $114(12.2)$ & $55(10.8)$ & \\
\hline $46-61$ & I, II (43.4) & $459(49.1)$ & $254(49.8)$ & \\
\hline $62-77$ & $1,217(47.3)$ & $362(38.7)$ & $201(39.4)$ & \\
\hline Gender & & & & $<0.0001$ \\
\hline Male & $\mathrm{I}, 4 \mathrm{I} 4(55.0)$ & $416(44.5)$ & $172(33.7)$ & \\
\hline Female & $1,159(45.0)$ & $519(55.5)$ & $338(66.3)$ & \\
\hline Race/ethnicity & & & & 0.0042 \\
\hline African-American & $542(21.1)$ & $195(20.9)$ & $110(21.6)$ & \\
\hline Asian-American & $357(13.9)$ & $85(9.1)$ & $28(5.5)$ & \\
\hline Filipino & $270(10.5)$ & $98(10.5)$ & $51(10.0)$ & \\
\hline Latino & $435(16.9)$ & $186(19.9)$ & $106(20.8)$ & \\
\hline Other/unknown/multiracial & $387(15.0)$ & $144(15.4)$ & $92(18.0)$ & \\
\hline Caucasian & $582(22.6)$ & $227(24.3)$ & $123(24.1)$ & \\
\hline Marital status $(\mathrm{n}=3,989)$ & & & & $<0.0001$ \\
\hline Single, separated, divorced, or widowed & $706(27.6)$ & $311(33.4)$ & $179(35.7)$ & \\
\hline Married or partnered & I,852 (72.4) & $619(66.6)$ & $322(64.3)$ & \\
\hline Education $(n=3,958)$ & & & & $<0.000$ I \\
\hline Less than high school graduate & $314(12.4)$ & $|4|(\mid 5.3)$ & $97(19.3)$ & \\
\hline High school graduate or greater & $2,220(87.6)$ & $779(84.7)$ & $407(80.8)$ & \\
\hline Any diabetes complication & $487(18.9)$ & $210(22.5)$ & $158(31.0)$ & $<0.0001$ \\
\hline Number of chronic medications, mean (SD) & $5.6(2.9)$ & $6.3(3.3)$ & $7.3(3.9)$ & $<0.0001$ \\
\hline
\end{tabular}

Notes: None: PHQ-8 =0-4; mild: PHQ-8 =5-9; moderate/severe: PHQ-8 $\geqq 10$. Values are presented as $\mathrm{n}(\%)$ in table unless otherwise indicated. Abbreviations: PHQ, Patient Health Questionnaire; SD, standard deviation. 
Table 2 Association between depressive symptom severity and cardiometabolic medication adherence for 4,018 adults with type 2 diabetes

\begin{tabular}{|c|c|c|c|c|c|c|}
\hline & \multirow{3}{*}{$\begin{array}{l}\text { Trend test } \\
P \text {-value }^{\mathrm{b}}\end{array}$} & \multicolumn{5}{|c|}{ Depressive symptom severity } \\
\hline & & \multirow{2}{*}{$\begin{array}{l}\text { None, } \\
\text { PHQ =0-4 } \\
\text { Estimated \% }\end{array}$} & \multicolumn{2}{|l|}{ Mild, PHQ =5-9 } & \multicolumn{2}{|c|}{ Moderate/severe, $\mathrm{PHQ} \geq 10$} \\
\hline & & & $\begin{array}{l}\text { Estimated \% } \\
\text { difference }(95 \% \mathrm{Cl})\end{array}$ & $\operatorname{RR}(95 \% \mathrm{Cl})$ & $\begin{array}{l}\text { Estimated } \% \\
\text { difference }(95 \% \mathrm{Cl})\end{array}$ & RR (95\% Cl) \\
\hline \multicolumn{7}{|c|}{ Early nonadherence } \\
\hline Unadjusted & $<0.0001$ & 25.2 & $+4.4(-0.5,+9.3)$ & I. $18(0.99,1.40)$ & $+8.3(+2.0,+14.6)$ & $1.33(1.09,1.62)$ \\
\hline Adjusted $^{\mathrm{a}}$ & 0.003 & 25.9 & $+2.9(-2.0,+7.9)$ & $1.12(0.94,1.33)$ & $+5.3(-I . I,+I I .8)$ & $1.20(0.97,1.48)$ \\
\hline \multicolumn{7}{|c|}{ Overall nonadherence (NPMG > 20\%) } \\
\hline Unadjusted & 0.0002 & 36.0 & $+3.9(-1.6,+9.5)$ & I.II $(0.96$, I.28) & $+7.8(+0.8,+14.7)$ & $1.22(1.03,1.44)$ \\
\hline Adjusted $^{a}$ & 0.012 & 36.7 & $+2.0(-3.5,+7.4)$ & $1.06(0.92,1.22)$ & $+5.2(-1.8,+12.1)$ & I.I4 (0.96, I.35) \\
\hline \multicolumn{7}{|l|}{ NPMG } \\
\hline Unadjusted & 0.0007 & 24.9 & $+2.5(+0.1,+5.0)$ & $\mathrm{n} / \mathrm{a}$ & $+4.9(+1.8,+8.0)$ & $\mathrm{n} / \mathrm{a}$ \\
\hline Adjusted $^{\mathrm{a}}$ & 0.019 & 25.3 & $+1.3(-1.1,+3.7)$ & $n / a$ & $+3.7(+0.6,+6.8)$ & $\mathrm{n} / \mathrm{a}$ \\
\hline
\end{tabular}

Notes: Results are reported as the estimated percentage of individuals (early nonadherence, overall nonadherence [NPMG > 20\%]) or the NPMG (estimated percentage of days without medication supply over 24 months). ${ }^{a}$ Due to missing covariates, adjusted models have $\mathrm{n}=3,989$. Models are adjusted for age, gender, race/ethnicity, marital status,

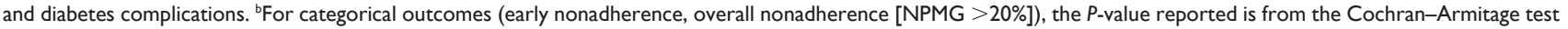
for trend; for the continuous outcome (NPMG), the $P$-value reported is for the linear trend based on a linear regression model.

Abbreviations: $\mathrm{Cl}$, confidence interval; n/a, not applicable; NPMG, new prescription medication gap; PHQ, Patient Health Questionnaire; RR, relative risk.

linear trend between depression and nonadherence (NPMG: $P=0.0007$ [unadjusted] and $P=0.019$ [adjusted]).

\section{Discussion}

Among adults with diabetes, associations between depressive symptom severity and adherence to cardiometabolic medications were modest for indicators of both early and long-term adherence over 24 months, which extends prior research focused on secondary adherence. ${ }^{14,15}$ These findings are relevant because initiating and maintaining long-term adherence are important for optimal control of cardiometabolic risk factors and for prevention of associated diabetes complications and mortality.

The $5 \%$ greater rate of early nonadherence among patients with depressive symptoms is clinically significant, given these patients never become ongoing medication users. A graded pattern was observed between greater depressive symptom severity and poorer adherence. The finding from the present study differs from prior research in hypertensive patients from the same source population (KPNC) which did not detect an association between depression and early nonpersistence to antihypertensive medications. ${ }^{32}$ Unlike the prior study that classified depression based on electronic medical records (ie, clinically recognized depression), the present study classified depression based on direct assessment of patient-reported symptoms using the PHQ-8. Thus, the present sample was not limited to people whose depression was clinically recognized. ${ }^{9,33}$ This expanded exposure definition may explain the difference in findings and supports the value of patient-reported outcome measures and the use of dimensional measures for studies of mental disorders such as depression. The findings are consistent with prior research reporting that the association between depression and nonadherence is not limited to those with probable major depression. ${ }^{34}$ Diabetes distress has also been associated with nonadherence; however, it is believed diabetes distress is unlikely to explain the association between depression and nonadherence. Prior research has found that the association between diabetes distress and adherence does not persist after depressive symptoms are accounted for, whereas in that study depression was independently associated with adherence after diabetes distress was taken into account. ${ }^{35}$

Whereas early nonadherence reflects discrete behaviors at two specific points in time, NPMG is an aggregate indicator that reflects the cumulative effect of repeated utilization (or lack thereof) over a period of 24 months. This difference may be informative for tertiary prevention efforts, namely, the development of interventions to address suboptimal medication adherence among adults with depressive symptoms. The present findings suggest that medication adherence interventions for people with comorbid depression may need to be applied both at the initiation of treatment and on an ongoing basis to sustain adherence over time.

\section{Limitations}

Some study limitations should be considered. Patterns of adherence were examined for a limited set of cardiometabolic medication classes and indications, and only the first 
new prescription was included within a medication class. Thus, the study findings may not generalize to other patient populations, multiple prescriptions within therapeutic classes, ongoing use of medications, or other types of medications. The estimates of nonadherence based on pharmacy utilization data are conservative, given that it is unknown whether any medications dispensed were actually consumed because medication-taking and prescription filling are distinct behaviors. Research indicates that the use of pharmacy utilization measures of adherence results in lesser effects for depression than when self-report adherence measures are used; ${ }^{16}$ therefore, the results from the present study represent conservative estimates of the true effects of depression. Nevertheless, these findings are based on objective measures of utilization according to the methods that have been previously validated, ${ }^{6}$ thus avoiding concerns of recall bias or social desirability associated with retrospective, self-reported medication adherence.

In this study, depressive symptoms were assessed at a single point in time that preceded a new prescription by no more than 1 year and based on self-report (using the PHQ-8). Although depressive symptoms fluctuate over time, evidence suggests that depression is often recurrent and chronic among adults with diabetes ${ }^{36}$ and often not clinically recognized..$^{9,33}$ The presence of consistent associations between depressive symptoms and adherence over the long term supports the enduring nature of the risk for nonadherence associated with depressive symptoms and suggests that these findings may be conservative because the observed associations may have been attenuated by the small delay between the measurement of depressive symptoms and adherence in some participants. A minority of individuals who scored in the moderate/severe range on the PHQ-8 likely would not have met criteria for major depression or another clinically significant depressive disorder and may instead have a related condition such as an anxiety disorder or diabetes distress that presents with substantial comorbid depressive symptomatology. This is not viewed as a limitation because the present findings generalize to a broader group of people, those with at least one PHQ-8 score of 10 or greater, who can be identified easily in routine practice settings. Moreover, using PHQ scores to identify patients at an increased risk for nonadherence is consistent with recommendations from a recent issue brief from the Office of the National Coordinator for Health Information Technology to develop predictive analytics based on electronic medical record data to enable targeted interventions. ${ }^{37}$ The present study found a significant, graded relationship between depressive symptom severity and nonadherence for all measures, which affirms the utility of depressive symptoms as a dimensional construct in understanding its association with adherence, regardless of the extent that symptoms overlap with related constructs such as diabetes distress. Because all participants in this study were insured and received services via KPNC, which includes integrated pharmacy services, results may not generalize to disadvantaged patient populations or safety net health care settings. Although the large sample was ethnically and socioeconomically diverse, the findings may not reflect patterns in settings where access to care differs across social groups. Although initial data collection occurred in 2005-2006, depression identification, care, and adherence remain persistent clinical challenges. ${ }^{2,38}$ However, it is not believed that the overall relationship between depression and adherence would change substantively over time.

\section{Conclusion}

Clinicians treating patients with type 2 diabetes who prescribe new cardiometabolic therapies should be aware that those with depression are more likely to have elevated rates of nonadherence both initially and over the long term. However, it is likewise important to note that the differences attributable to depression were modest compared to the baseline high rate of nonadherence in the overall sample. Patients with type 2 diabetes and depression experience a disproportionately high burden of premature morbidity and mortality. ${ }^{39-42}$ The small increased probability of nonadherence among patients with type 2 diabetes and comorbid depression should not deter clinicians from initiating cardiometabolic therapies. Rather, such treatments should be offered alongside care for depression, and interventions to address adherence should be delivered longitudinally to target the barriers that depressed patients face to maintaining adherence. Promising interventions, such as the routine assessment of medication adherence, exploration of barriers and problem-solving, and use of motivational interviewing to facilitate behavior change, ${ }^{43-45}$ may need to be offered when medications are initiated and implemented repeatedly in a routine clinical practice. Although recognition of depression and appropriate treatment are necessary for improving depression outcomes, these alone may be insufficient to improve self-care and outcomes for people with type 2 diabetes. ${ }^{46}$ To optimally treat patients with comorbid type 2 diabetes and depression and prevent diabetes complications, clinicians should pair interventions that address depressive symptoms with interventions that directly target diabetes self-care, including sustained medication adherence. ${ }^{44,47}$ Future research should examine the effectiveness of such paired interventions for people with comorbid diabetes and depression on adherence and clinical 
outcomes and evaluate interventions both at the time of initial medication prescription and over the long term.

\section{Acknowledgments}

The authors wish to acknowledge the untimely loss of coauthor and mentor Wayne J Katon. Dr Katon was instrumental in building the collaborations that led to this research. He has inspired researchers for decades to improve understanding of the bidirectional relationships between depression and chronic diseases, particularly diabetes, and to endeavor to improve physical and mental health for those affected. Dr Katon's contributions have touched the lives of countless patients, colleagues, and friends and the authors are deeply grateful. This research was supported by funding from the National Institutes of Health (R01-DK065664, R01DK080726, R01-DK081796, P30-DK092924, NLM01235501A1, and National Center for Advancing Translational Sciences Grant KL2 TR000421) and the Kaiser Permanente Northern California Community Benefit Program.

\section{Disclosure}

The authors report no conflicts of interest in this work.

\section{References}

1. Simpson SH, Eurich DT, Majumdar SR, et al. A meta-analysis of the association between adherence to drug therapy and mortality. BMJ. 2006;333(7557):15.

2. Benjamin RM. Medication adherence: helping patients take their medicines as directed. Public Health Rep. 2012;127(1):2-3.

3. Christensen AJ, Howren MB, Hillis SL, et al. Patient and physician beliefs about control over health: association of symmetrical beliefs with medication regimen adherence. J Gen Intern Med. 2010;25(5): 397-402.

4. Krass I, Schieback P, Dhippayom T. Adherence to diabetes medication: a systematic review. Diabet Med. 2015;32(6):725-737.

5. Raebel MA, Schmittdiel J, Karter AJ, Konieczny JL, Steiner JF. Standardizing terminology and definitions of medication adherence and persistence in research employing electronic databases. Med Care 2013;51(8 Suppl 3):S11-S21.

6. Karter AJ, Parker MM, Moffet HH, Ahmed AT, Schmittdiel JA, Selby JV. New prescription medication gaps: a comprehensive measure of adherence to new prescriptions. Health Serv Res. 2009;44(5 Pt 1): 1640-1661.

7. Raebel MA, Ellis JL, Carroll NM, et al. Characteristics of patients with primary non-adherence to medications for hypertension, diabetes, and lipid disorders. J Gen Intern Med. 2012;27(1):57-64.

8. Anderson RJ, Freedland KE, Clouse RE, Lustman PJ. The prevalence of comorbid depression in adults with diabetes: a meta-analysis. Diabetes Care. 2001;24(6):1069-1078.

9. Katon WJ, Simon G, Russo J, et al. Quality of depression care in a population-based sample of patients with diabetes and major depression. Med Care. 2004;42(12):1222-1229.

10. Li C, Ford ES, Strine TW, Mokdad AH. Prevalence of depression among U.S. adults with diabetes: findings from the 2006 behavioral risk factor surveillance system. Diabetes Care. 2008;31(1):105-107.

11. Bouwman V, Adriaanse MC, van't Riet E, Snoek FJ, Dekker JM, Nijpels G. Depression, anxiety and glucose metabolism in the general Dutch population: the new Hoorn study. PLoS One. 2010; 5(4):e9971.
12. Nouwen A, Nefs G, Caramlau I, et al. Prevalence of depression in individuals with impaired glucose metabolism or undiagnosed diabetes: a systematic review and meta-analysis of the European Depression in Diabetes (EDID) Research Consortium. Diabetes Care. 2011;34(3): $752-762$.

13. Roy T, Lloyd CE. Epidemiology of depression and diabetes: a systematic review. J Affect Disord. 2012;142(Suppl):S8-S21.

14. Lin EH, Katon W, Von Korff M, et al. Relationship of depression and diabetes self-care, medication adherence, and preventive care. Diabetes Care. 2004;27(9):2154-2160.

15. Katon W, Russo J, Lin EH, et al. Diabetes and poor disease control: is comorbid depression associated with poor medication adherence or lack of treatment intensification? Psychosom Med. 2009;71(9): 965-972.

16. Grenard JL, Munjas BA, Adams JL, et al. Depression and medication adherence in the treatment of chronic diseases in the United States: a meta-analysis. J Gen Intern Med. 2011;26(10):1175-1182.

17. Karter AJ, Ferrara A, Liu JY, Moffet HH, Ackerson LM, Selby JV. Ethnic disparities in diabetic complications in an insured population. JAMA. 2002;287(19):2519-2527.

18. Moffet HH, Adler N, Schillinger D, et al. Cohort profile: The Diabetes Study of Northern California (DISTANCE) - objectives and design of a survey follow-up study of social health disparities in a managed care population. Int J Epidemiol. 2009;38(1):38-47.

19. Kroenke K, Strine TW, Spitzer RL, Williams JB, Berry JT, Mokdad AH. The PHQ-8 as a measure of current depression in the general population. $J$ Affect Disord. 2009;114(1-3):163-173.

20. Kroenke K, Spitzer RL, Williams JB, Lowe B. The Patient Health Questionnaire Somatic, Anxiety, and Depressive Symptom Scales: a systematic review. Gen Hosp Psychiatry. 2010;32(4):345-359.

21. Spitzer RL, Kroenke K, Williams JB. Validation and utility of a selfreport version of PRIME-MD: the PHQ primary care study. Primary Care Evaluation of Mental Disorders. Patient Health Questionnaire. JAMA. 1999;282(18):1737-1744.

22. Spitzer RL, Williams JB, Kroenke K, Hornyak R, McMurray J. Validity and utility of the PRIME-MD patient health questionnaire in assessment of 3000 obstetric-gynecologic patients: the PRIME-MD Patient Health Questionnaire Obstetrics-Gynecology Study. Am JObstet Gynecol. 2000; 183(3):759-769.

23. Kroenke K, Spitzer RL, Williams JB. The PHQ-9: validity of a brief depression severity measure. J Gen Intern Med. 2001;16(9):606-613.

24. Huang FY, Chung H, Kroenke K, Delucchi KL, Spitzer RL. Using the patient health questionnaire-9 to measure depression among racially and ethnically diverse primary care patients. J Gen Intern Med. 2006; 21(6):547-552.

25. Gilbody S, Richards D, Brealey S, Hewitt C. Screening for depression in medical settings with the Patient Health Questionnaire (PHQ): a diagnostic meta-analysis. J Gen Intern Med. 2007;22(11):1596-1602.

26. Parker MM, Moffet HH, Adams A, Karter AJ. An algorithm to identify medication nonpersistence using electronic pharmacy databases. $J$ Am Med Inform Assoc. 2015;22(5):957-961.

27. Zou G. A modified Poisson regression approach to prospective studies with binary data. Am J Epidemiol. 2004;159(7):702-706.

28. Cheung YB. A modified least-squares regression approach to the estimation of risk difference. Am J Epidemiol. 2007;166(11):1337-1344.

29. Greenland S, Pearl J, Robins JM. Causal diagrams for epidemiologic research. Epidemiology. 1999;10(1):37-48.

30. Hernan MA, Hernandez-Diaz S, Werler MM, Mitchell AA. Causal knowledge as a prerequisite for confounding evaluation: an application to birth defects epidemiology. Am J Epidemiol. 2002; 155(2):176-184

31. Horvitz DG, Thompson DJ. A generalization of sampling without replacement from a finite universe. J Am Stat Assoc. 1952;47(260) 663-685.

32. Schmittdiel JA, Dyer W, Uratsu C, et al. Initial persistence with antihypertensive therapies is associated with depression treatment persistence, but not depression. J Clin Hypertens (Greenwich). 2014; 16(6):412-417. 
33. Hudson DL, Karter AJ, Fernandez A, et al. Differences in the clinical recognition of depression in diabetes patients: the Diabetes Study of Northern California (DISTANCE). Am J Manag Care. 2013;19(5):344-352.

34. Gonzalez JS, Safren SA, Cagliero E, et al. Depression, self-care, and medication adherence in type 2 diabetes: relationships across the full range of symptom severity. Diabetes Care. 2007;30(9):2222-2227.

35. Gonzalez JS, Delahanty LM, Safren SA, Meigs JB, Grant RW. Differentiating symptoms of depression from diabetes-specific distress: relationships with self-care in type 2 diabetes. Diabetologia. 2008;51(10): $1822-1825$.

36. Katon WJ, Von Korff M, Lin EH, et al. The Pathways Study: a randomized trial of collaborative care in patients with diabetes and depression. Arch Gen Psychiatry. 2004;61(10):1042-1049.

37. Williams A. Issue Brief: Medication Adherence and Health IT. Office of the National Coordinator for Health Information Technology; 2014. Available from: https://www.healthit.gov/sites/default/files/medication adherence_and_hit_issue_brief.pdf. Accessed February 28, 2017.

38. Olfson M, Blanco C, Marcus SC. Treatment of adult depression in the United States. JAMA Intern Med. 2016;176(10):1482-1491.

39. de Groot M, Anderson R, Freedland KE, Clouse RE, Lustman PJ. Association of depression and diabetes complications: a meta-analysis. Psychosom Med. 2001;63(4):619-630.
40. Katon WJ, Rutter C, Simon G, et al. The association of comorbid depression with mortality in patients with type 2 diabetes. Diabetes Care. 2005;28(11):2668-2672.

41. Katon W, Lyles CR, Parker MM, Karter AJ, Huang ES, Whitmer RA. Association of depression with increased risk of dementia in patients with type 2 diabetes: the Diabetes and Aging Study. Arch Gen Psychiatry. 2012;69(4):410-417.

42. Sullivan MD, O’Connor P, Feeney $\mathrm{P}$, et al. Depression predicts allcause mortality: epidemiological evaluation from the ACCORD HRQL substudy. Diabetes Care. 2012;35(8):1708-1715.

43. Murawski ME, Milsom VA, Ross KM, et al. Problem solving, treatment adherence, and weight-loss outcome among women participating in lifestyle treatment for obesity. Eat Behav. 2009;10(3):146-151.

44. Katon WJ, Lin EH, Von Korff M, et al. Collaborative care for patients with depression and chronic illnesses. N Engl J Med. 2010;363(27): 2611-2620.

45. White RD. Patient empowerment and optimal glycemic control. Curr Med Res Opin. 2012;28(6):979-989.

46. Lin EH, Katon W, Rutter C, et al. Effects of enhanced depression treatment on diabetes self-care. Ann Fam Med. 2006;4(1):46-53.

47. Markowitz SM, Gonzalez JS, Wilkinson JL, Safren SA. A review of treating depression in diabetes: emerging findings. Psychosomatics. 2011;52(1):1-18. 


\section{Supplementary materials}

Table SI Classification of cardiometabolic medications

\begin{tabular}{|c|c|}
\hline Therapeutic category & Medication name(s) \\
\hline \multirow[t]{6}{*}{ Oral antihyperglycemic agent } & Glimepiride \\
\hline & Glipidize \\
\hline & Glyburide \\
\hline & Metformin \\
\hline & Tolazamide \\
\hline & Tolbutamide \\
\hline \multirow[t]{30}{*}{ Antihypertensive agent } & Amlodipine \\
\hline & Atenolol \\
\hline & Benazepril \\
\hline & Bisoprolol \\
\hline & Bumetanide \\
\hline & Captopril \\
\hline & Carvedilol \\
\hline & Chlorthalidone \\
\hline & Diltiazem \\
\hline & Enalapril \\
\hline & Ethacrynic \\
\hline & Felodipine \\
\hline & Furosemide \\
\hline & Hydrochlorothiazide \\
\hline & Indapamide \\
\hline & Labetalol \\
\hline & Lisinopril \\
\hline & Losartan \\
\hline & Metolazone \\
\hline & Metoprolol \\
\hline & Nadolol \\
\hline & Nifedipine \\
\hline & Propranolol \\
\hline & Ramipril \\
\hline & Spironolactone \\
\hline & Spironolactone/hydrochlorothiazide \\
\hline & Torsemide \\
\hline & Triamterene/hydrochlorothiazide \\
\hline & Valsartan \\
\hline & Verapamil \\
\hline \multirow[t]{4}{*}{ Lipid-lowering agent } & Atorvastatin \\
\hline & Fluvastatin \\
\hline & Pravastatin \\
\hline & Simvastatin \\
\hline
\end{tabular}

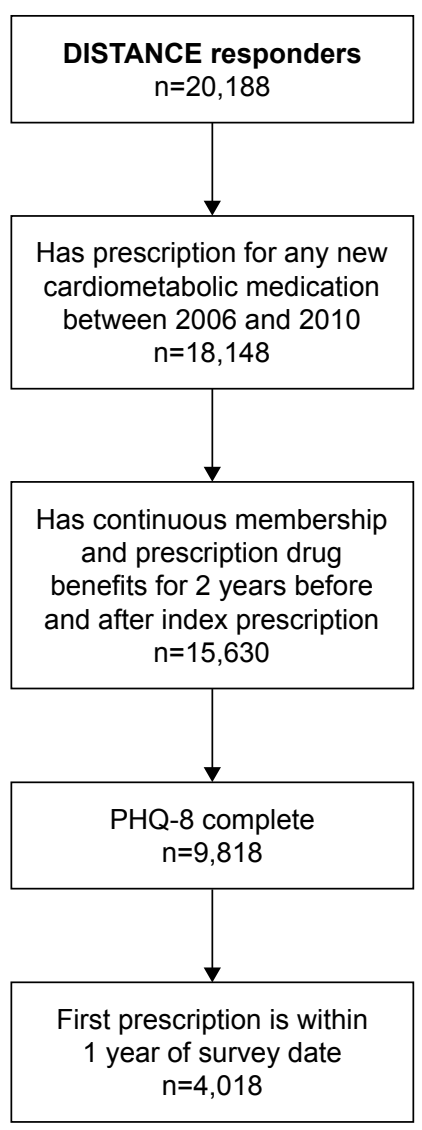

Figure SI Flowchart of new cardiometabolic medication user cohort.

Abbreviations: DISTANCE, the Diabetes Study of Northern California; PHQ, Patient Health Questionnaire. 


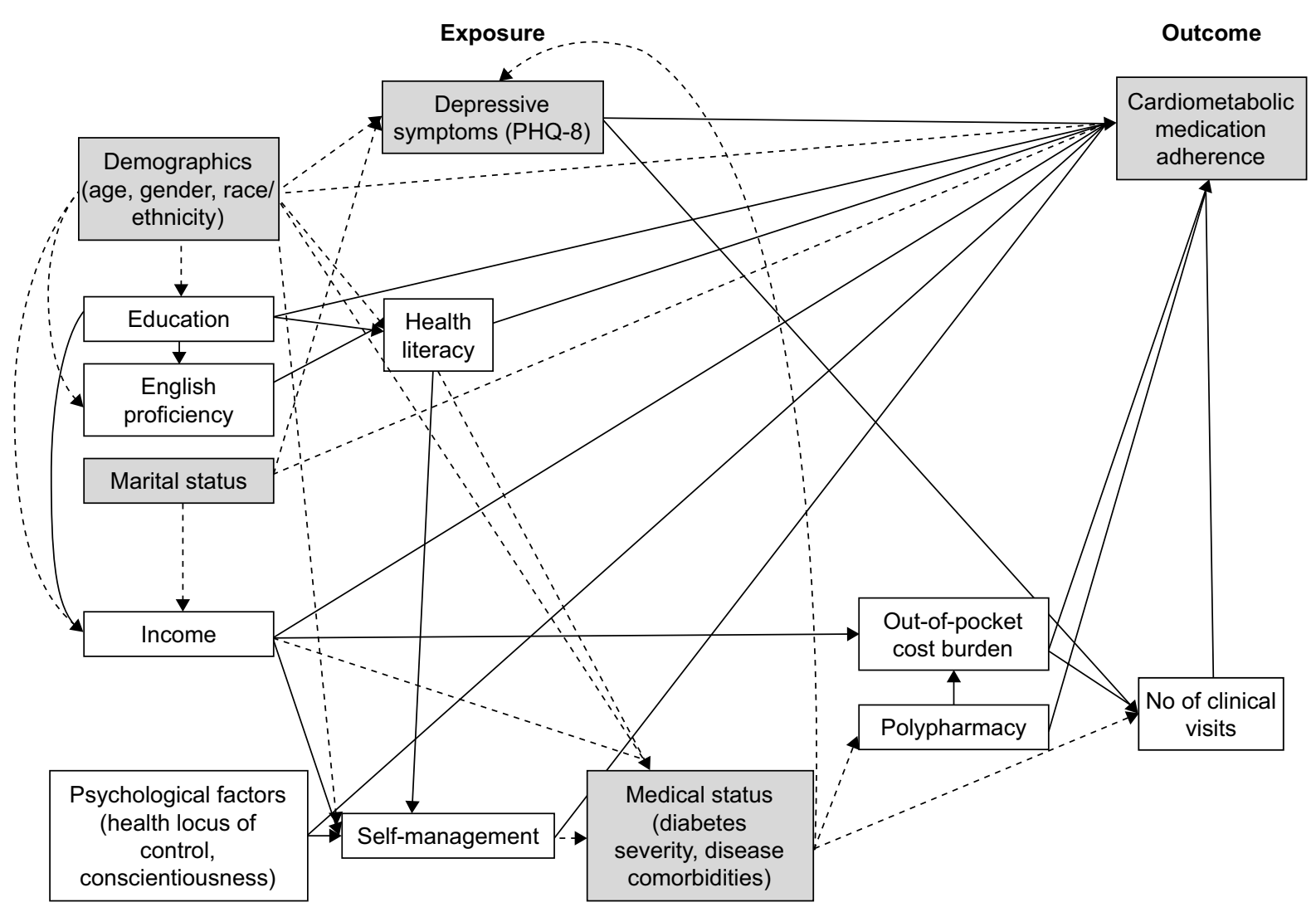

Figure S2 DAG demonstrating covariate selection.

Notes: Shaded box: variable included in multivariate analyses; white box: variable excluded as potential confounder and therefore not included in multivariate analyses; solid arrow: causal pathways that do not confound the association between depressive symptoms and cardiometabolic medication adherence; dotted arrow: causal pathways that potentially confound the association between depressive symptoms and cardiometabolic medication adherence in unadjusted analyses but are no longer confounders in multivariate models that include the variables identified in the shaded boxes. The DAG was constructed to illustrate the hypothesized causal relationships and time ordering between variables associated with depressive symptoms and cardiometabolic medication adherence. All of the variables represented were available in the DISTANCE data set. Analysis of the DAG followed an established process to identify which of these variables were potential confounders of the association between depressive symptoms and adherence.' This analysis revealed that adjustments for the variables in the shaded boxes (age, gender, race/ethnicity, marital status, and diabetes complications) were necessary and sufficient to address potential confounding variables, whereas variables in the white boxes were excluded as covariates because they did not function as potential confounders. Causal pathways illustrated by the gray dotted arrows are accounted for by adjustment of the identified covariates, and therefore, these relationships do not confound the association between depressive symptoms and adherence. This includes all variables with casual links to the independent variable, depressive symptoms. The remaining causal relationships (solid arrows) do not function as confounders and therefore do not require adjustment. This is visualized in the graph because variables that are causally associated with the dependent variable (variables in white boxes that have solid arrows to adherence) are not causally associated with the independent variable (these variables do not have solid arrows terminating at depressive symptoms).

Abbreviations: DAG, directed acyclic graph; DISTANCE, the Diabetes Study of Northern California; PHQ, Patient Health Questionnaire.

\section{Reference}

1. Greenland S, Pearl J, Robins JM. Causal diagrams for epidemiologic research. Epidemiology. 1999;10(1):37-48.

\section{Publish your work in this journal}

Patient Preference and Adherence is an international, peer-reviewed, open access journal that focuses on the growing importance of patient preference and adherence throughout the therapeutic continuum. Patient satisfaction, acceptability, quality of life, compliance, persistence and their role in developing new therapeutic modalities and compounds to optimize clinical outcomes for existing disease states are major areas of interest for the journal. This journal has been accepted for indexing on PubMed Central. The manuscript management system is completely online and includes a very quick and fair peer-review system, which is all easy to use. Visit http://www. dovepress.com/testimonials.php to read real quotes from published authors. 